\title{
BOARD GENDER DIVERSITY: SUATU TELAAH PUSTAKA
}

\author{
Bhenu Artha ${ }^{1}$ \\ Ali Jufri ${ }^{* *}$ \\ ${ }^{1}$ Universitas Widya Mataram \\ Email: bhenoz27@gmail.com \\ ${ }^{2}$ Universitas Muhammadiyah Cirebon \\ Email: jufri.ali2014@gmail.com \\ *Coresponden Author
}

\begin{abstract}
Abstrak
Tujuan penelitian adalah ini untuk mengetahui keterkaitan board gender diversity dengan variabelvariabel lain. Board gender merupakan faktor penting yang mempengaruhi keputusan strategis perusahaan. Penelitian ini menggunakan studi literatur (literature review) sebagai metodologi penelitian. Penelitian ini menunjukkan hasil bahwa keragaman gender dewan (board gender diversity) berpengaruh positif terhadap stock price informativeness, firm performance, sustainability reporting quality, internal control weaknesses, corporate social responsibility (CSR), CEO's base pay dan compensation inequality, corporate risk, dividend payouts, renewable energy consumption, corporate innovation, firm profitability, biodiversity disclosures, cross listing, organizational performance, corporate environmental responsibility, financial reporting quality, firm performance pada negara dengan high national governance quality. Penelitian ini juga memperlihatkan bahwa dividend payments, capital structure, technical efficiency, $R \& D$ investments, cost of bank loans, stock price cash risk, firm performance pada negara dengan low national governance quality berbanding terbalik dengan board gender diversity. Hasil selanjutnya adalah board gender diversity tidak berpengaruh terhadap firm risk.
\end{abstract}

Kata kunci: board gender diversity, telaah pustaka

\section{PENDAHULUAN}

Keragaman dewan atau board diversity dapat dianggap sebagai sumber keunggulan kompetitif (Cox dan Blake, 1991). Keragaman dan kinerja organisasi memiliki hubungan positif, berdasarkan pandangan berbasis sumber daya perusahaan (Barney, 1991). Kinerja organisasi secara langsung berhubungan dengan manajemen organisasi, maka penelitian tentang keragaman demografis manajemen merupakan suatu topik yang penting (Şener \& Karaye, 2014). Keragaman demografis dewan mengacu pada komposisi anggota dewan meliputi usia, jenis kelamin, latar belakang pendidikan, etnis, kebangsaan, dan pengalaman (Coffey dan Wang, 1998; Erhardt dkk, 2003). Keragaman gender dewan mempengaruhi konflik yang terkait dengan tugas dan bagaimana konflik tersebut mempengaruhi kinerja organisasi (van den Oever \& Beerens, 2020).

Keragaman gender menjadi salah satu dimensi keberagaman yang penting bagi organisasi, karena peningkatan persentase karyawan wanita, maka keragaman gender menjadi hal yang penting di semua organisasi (Şener \& Karaye, 2014). Keragaman gender dewan didasarkan pada argumen etis dan ekonomis, serta terdapat hubungan positif antara keragaman gender dewan dengan nilai perusahaan (Campbell dan Minguez-Vera, 2008). Penelitian yang dilaksanakan Carter dkk (2003) menunjukkan bahwa perusahaan yang menunjuk setidaknya dua direksi wanita memiliki kinerja organisasi yang lebih baik. Perubahan dalan keragaman dewan lebih responsive terhadap negosiasi pribadi (withdrawn proposals) daripada tekanan eksternal (voted proposals) (Rastad \& Dobson, 2020). Lingkungan kelembagaan yang baik dapat melemahkan pengaruh dewan keragaman gender pada pembayaran dividen dan kepemilikan institusional berhubungan positif dengan dewan keragaman gender dan pembayaran dividen perusahaan meningkat ketika para eksekutif senior perempuan memiliki kepemilikan saham (Ye et al., 2019).

Keragaman dewan terdiri dari dua macam yaitu yang dapat diamati dan yang kurang terlihat, yang dapat diamati termasuk keanekaragaman kebangsaan, usia, jenis kelamin, dan latar belakang etnis, sementara yang kurang dapat diamati meliputi pendidikan, pengalaman kerja, keanggotaan organisasi, dan latar belakang fungsional pekerjaannya (Kang dkk, 2007). Kemajuan signifikan dalam representasi 
wanita pada dewan direksi beriringan dengan keragaman gender yang meningkat signifikan pada awalnya dapat dilihat pada penelitian Dalton dkk (1999). Board gender khususnya kehadiran direktur wanita adalah hal penting dalam tata kelola perusahaan (Carter dkk, 2003). Konsep keberagaman dewan menunjukkan bahwa dewan perusahaan harus dirancang dengan mencerminkan struktur masyarakat yang baik dengan representasi jenis kelamin, etnis, dan latar belakang professional yang sesuai (Şener \& Karaye, 2014). Keragaman dewan didukung oleh teori tata kelola perusahaan atas dasar kewajiban moral kepada pemegang saham, pemangku kepentingan, sumber, dan alokasi sumber daya (Keasey dkk, 1997; Hampel, 1998; Daily dan Dalton, 1993). Bank berinvestasi pada asset yang lebih berisiko ketika direktur wanita merasakan manfaat positif dari investasi berisiko (pada bank yang memiliki regulasi rasio modal lebih besar dan atau bermodal cukup), dan bank berinvestasi pada posisi yang lebih berisiko ketika kekuasaan bergeser darinya karena kepemilikan ekuitas chief executive officer (Abou-El-Sood, 2021).

Peningkatan keragaman gender dewan lebih responsif terhadap withdrawn proposals daripada voted proposals, dan bahwa suara pemegang saham yang mendukung keberagaman lebih tinggi ketika dewan kurang beragam (Rastad \& Dobson, 2020). Direktur wanita pada perusahaan dengan corporate social responsibility (CSR) rendah seringkali ditekan untuk melepaskan kekuasaan efektif mereka di dewan, dan sering dibatasi untuk mencegah stigmatisasi dan marginalisasi sosial (Maria Giuseppina Brunaa \& Rey Đặng, Aymen Ammari, n.d.). Pengangkatan direktur wanita yang cenderung diam, tanpa adanya dorongan kritik, reflektivitas, kreativitas dan pembelejaran berkelanjutan, akan mengakibatkan berkurangnya keefektifan kebijakan CSR (Bruna dkk, 2020). Keragaman gender dewan berlaku ketika jumlah direktur wanita di dewan perusahaan mencapai ambang tiga, dan dimoderasi positif oleh kualitas tata kelola nasional dengan kinerja perusahaan, serta hal ini hanya terjadi di negara-negara dengan kualitas tata kelola nasional yang tinggi (Nguyen dkk, 2021).

Hambatan dalam menghasilkan menghasilkan potensi tidak hanya untuk kesetaraan gender tingkat dewan untuk dicapai, tetapi juga bagi organisasi untuk mendapatkan keuntungan yang besar (Geletkanycz, 2020). Datta, Doan, dan Toscano (2021) dalam penelitiannya menyampaikan bahwa eksekutif wanita lebih memilih struktur hutang dengan jatuh tempo yang lebih pendek, namun pengaruhnya terhadap utang jatuh tempo berbanding terbalik dengan proporsi kompensasi mereka. Beberapa factor sistematis dikaitkan dengan keragaman gender yang lebih besar untuk dewan pengawas dan manajemen diantara perusahaan swasta dan publik: faktor yang sama dapat menujukkan korelasi positif dengan dewan manajemen, dan korelasi negatif dengan dewan pengawas, atau sebaliknya (Tyrowicz et al., 2020). Yarram dan Adapa (2021) mengemukakan bahwa baik dimensi positif maupun negative dari CSR tidak terkait dengan keragaman gender Ketika ada representasi wanita di dewan direksi, namun perusahaan yang telah meningkatkan keseimbangan gender melakukan aktivitas CSR yang lebih positif dan mengurangi aktivitas negatif atau kontroversial yang menghambat CSR.

\section{METODE PENELITIAN}

Penelitian ini menggunakan metode telaah pustaka (literature review) (Snyder, 2019), yang dapat digunakan sebagai pijakan penelitian di masa depan. Telaah pustaka (literature review) memiliki peran penting untuk semua jenis penelitian, antara lain dapat dijadikan pedoman, baik untuk kebijakan maupun pelaksanaan, dan memberikan petunjuk terutama dalam bidang tertentu (Snyder, 2019). Sumber data dalam penelitian ini bersumber dari laman sciencedirect.com yang berjumlah 24 artikel.

\section{HASIL PENELITIAN}

Hasil telaah pustaka dapat dilihat pada tabel berikut ini:

Tabel 1. Telaah Pustaka Board Gender Diversity

\begin{tabular}{|l|l|l|l|}
\hline Nama dan Tahun & \multicolumn{1}{|c|}{ Permasalahan } & \multicolumn{1}{c|}{ Variabel } & \multicolumn{1}{c|}{ Hasil } \\
\hline (Gul et al., 2011) & $\begin{array}{l}\text { Bagaimana } \\
\text { pengaruh } \\
\text { keragaman gender } \\
\text { dewan terhadap } \\
\text { stock price } \\
\text { informativeness? }\end{array}$ & $\begin{array}{l}\text { stock price } \\
\text { informativeness }\end{array}$ & $\begin{array}{l}\text { keragaman gender dewan } \\
\text { berpengaruh positif terhadap } \\
\text { stock price informativeness }\end{array}$ \\
\hline
\end{tabular}




\begin{tabular}{|c|c|c|c|}
\hline (Low et al., 2015) & $\begin{array}{l}\text { Bagaimana } \\
\text { pengaruh } \\
\text { keragaman gender } \\
\text { dewan terhadap } \\
\text { firm performance? }\end{array}$ & firm performance & $\begin{array}{l}\text { keragaman gender dewan } \\
\text { berpengaruh positif terhadap } \\
\text { firm performance }\end{array}$ \\
\hline (Sila et al., 2016) & $\begin{array}{l}\text { Bagaimana } \\
\text { pengaruh } \\
\text { keragaman gender } \\
\text { dewan terhadap } \\
\text { firm risk? }\end{array}$ & firm risk & $\begin{array}{l}\text { keragaman gender dewan } \\
\text { tidak berpengaruh terhadap } \\
\text { firm risk }\end{array}$ \\
\hline $\begin{array}{l}\text { (Al-Shaer \& } \\
\text { Zaman, 2016) }\end{array}$ & $\begin{array}{l}\text { Bagaimana } \\
\text { pengaruh } \\
\text { keragaman gender } \\
\text { dewan terhadap } \\
\text { sustainability } \\
\text { reporting quality? }\end{array}$ & $\begin{array}{l}\text { sustainability reporting } \\
\text { quality }\end{array}$ & $\begin{array}{l}\text { keragaman gender dewan } \\
\text { berpengaruh positif terhadap } \\
\text { sustainability reporting } \\
\text { quality }\end{array}$ \\
\hline (Chen et al., 2016) & $\begin{array}{l}\text { Bagaimana } \\
\text { pengaruh } \\
\text { keragaman gender } \\
\text { dewan terhadap } \\
\text { internal control } \\
\text { weaknesses? }\end{array}$ & $\begin{array}{l}\text { internal control } \\
\text { weaknesses }\end{array}$ & $\begin{array}{l}\text { keragaman gender dewan } \\
\text { berpengaruh positif terhadap } \\
\text { internal control weaknesses }\end{array}$ \\
\hline $\begin{array}{l}\text { (Nekhili et al., } \\
\text { 2017) }\end{array}$ & $\begin{array}{l}\text { Bagaimana } \\
\text { pengaruh } \\
\text { keragaman gender } \\
\text { dewan terhadap } \\
\text { CSR? }\end{array}$ & $\begin{array}{l}\text { corporate social } \\
\text { responsibility }(C S R)\end{array}$ & $\begin{array}{l}\text { keragaman gender dewan } \\
\text { berpengaruh positif terhadap } \\
C S R\end{array}$ \\
\hline $\begin{array}{l}\text { (Saeed \& Sameer, } \\
\text { 2017) }\end{array}$ & $\begin{array}{l}\text { Bagaimana } \\
\text { pengaruh } \\
\text { keragaman gender } \\
\text { dewan terhadap } \\
\text { dividend } \\
\text { payments? }\end{array}$ & dividend payments & $\begin{array}{l}\text { keragaman gender dewan } \\
\text { berpengaruh 195negatif } \\
\text { terhadap dividend payments }\end{array}$ \\
\hline $\begin{array}{l}\text { (Adusei \& Obeng, } \\
\text { 2019) }\end{array}$ & $\begin{array}{l}\text { Bagaimana } \\
\text { pengaruh } \\
\text { keragaman gender } \\
\text { dewan terhadap } \\
\text { capital structure? }\end{array}$ & capital structure & $\begin{array}{l}\text { keragaman gender dewan } \\
\text { berpengaruh negatif } \\
\text { terhadap capital structure }\end{array}$ \\
\hline $\begin{array}{l}\text { (Owen \& } \\
\text { Temesvary, 2019) }\end{array}$ & $\begin{array}{l}\text { Bagaimana } \\
\text { pengaruh } \\
\text { keragaman gender } \\
\text { dewan terhadap } \\
\text { CEO's base pay } \\
\text { dan compensation } \\
\text { inequality? }\end{array}$ & $\begin{array}{l}\text { CEO's base pay dan } \\
\text { compensation inequality }\end{array}$ & $\begin{array}{l}\text { keragaman gender dewan } \\
\text { berpengaruh positif terhadap } \\
\text { CEO's base pay dan } \\
\text { compensation inequality }\end{array}$ \\
\hline (Adusei, 2019) & $\begin{array}{l}\text { Bagaimana } \\
\text { pengaruh } \\
\text { keragaman gender } \\
\text { dewan terhadap } \\
\text { technical } \\
\text { efficiency? }\end{array}$ & technical efficiency & $\begin{array}{l}\text { keragaman gender dewan } \\
\text { berpengaruh negatif } \\
\text { terhadap technical efficiency }\end{array}$ \\
\hline $\begin{array}{l}\text { (Almor et al., } \\
\text { 2020) }\end{array}$ & $\begin{array}{l}\text { Bagaimana } \\
\text { pengaruh } \\
\text { keragaman gender }\end{array}$ & $R \& D$ investments & $\begin{array}{l}\text { keragaman gender dewan } \\
\text { berpengaruh negatif } \\
\text { terhadap } R \& D \text { investments }\end{array}$ \\
\hline
\end{tabular}




\begin{tabular}{|c|c|c|c|}
\hline & $\begin{array}{l}\text { dewan terhadap } \\
R \& D \text { investments? }\end{array}$ & & \\
\hline $\begin{array}{l}\text { (Poletti-Hughes \& } \\
\text { Briano-Turrent, } \\
\text { 2019) }\end{array}$ & $\begin{array}{l}\text { Bagaimana } \\
\text { pengaruh } \\
\text { keragaman gender } \\
\text { dewan } \\
\text { terhadapcorporate } \\
\text { risk? }\end{array}$ & corporate risk & $\begin{array}{l}\text { keragaman gender dewan } \\
\text { berpengaruh positif terhadap } \\
\text { corporate risk }\end{array}$ \\
\hline (Ye et al., 2019) & $\begin{array}{l}\text { Bagaimana } \\
\text { pengaruh } \\
\text { keragaman gender } \\
\text { dewan terhadap } \\
\text { dividend payouts? }\end{array}$ & dividend payouts & $\begin{array}{l}\text { keragaman gender dewan } \\
\text { berpengaruh positif terhadap } \\
\text { dividend payouts }\end{array}$ \\
\hline (Atif et al., 2020) & $\begin{array}{l}\text { Bagaimana } \\
\text { pengaruh } \\
\text { keragaman gender } \\
\text { dewan terhadap } \\
\text { renewable energy } \\
\text { consumption? }\end{array}$ & $\begin{array}{l}\text { renewable energy } \\
\text { consumption }\end{array}$ & $\begin{array}{l}\text { keragaman gender dewan } \\
\text { berpengaruh positif terhadap } \\
\text { renewable energy } \\
\text { consumption }\end{array}$ \\
\hline $\begin{array}{l}\text { (Attah-Boakye et } \\
\text { al., 2020) }\end{array}$ & $\begin{array}{l}\text { Bagaimana } \\
\text { pengaruh } \\
\text { keragaman gender } \\
\text { dewan terhadap } \\
\text { corporate } \\
\text { innovation? }\end{array}$ & corporate innovation & $\begin{array}{l}\text { keragaman gender dewan } \\
\text { berpengaruh positif terhadap } \\
\text { corporate innovation }\end{array}$ \\
\hline $\begin{array}{l}\text { (Rey Đặng, } \\
\text { L'Hocine Houanti, } \\
\text { Krishna Reddy, } \\
\text { n.d.) }\end{array}$ & $\begin{array}{l}\text { Bagaimana } \\
\text { pengaruh } \\
\text { keragaman gender } \\
\text { dewan terhadap } \\
\text { firm profitability? }\end{array}$ & firm profitability & $\begin{array}{l}\text { keragaman gender dewan } \\
\text { berpengaruh positif terhadap } \\
\text { firm profitability }\end{array}$ \\
\hline $\begin{array}{l}\text { (Haque \& Jones, } \\
\text { 2020) }\end{array}$ & $\begin{array}{l}\text { Bagaimana } \\
\text { pengaruh } \\
\text { keragaman gender } \\
\text { dewan terhadap } \\
\text { biodiversity } \\
\text { disclosures? }\end{array}$ & biodiversity disclosures & $\begin{array}{l}\text { keragaman gender dewan } \\
\text { berpengaruh positif terhadap } \\
\text { biodiversity disclosures }\end{array}$ \\
\hline $\begin{array}{l}\text { Karavitis, Kokas, } \\
\text { dan Tsoukas, } \\
(2020)\end{array}$ & $\begin{array}{l}\text { Bagaimana } \\
\text { pengaruh } \\
\text { keragaman gender } \\
\text { dewan terhadap } \\
\text { cost of bank loans? }\end{array}$ & cost of bank loans & $\begin{array}{l}\text { keragaman gender dewan } \\
\text { berpengaruh 196negatif } \\
\text { terhadap cost of bank loans }\end{array}$ \\
\hline $\begin{array}{l}\text { (Qayyum et al., } \\
\text { 2020) }\end{array}$ & $\begin{array}{l}\text { Bagaimana } \\
\text { pengaruh } \\
\text { keragaman gender } \\
\text { dewan terhadap } \\
\text { stock price cash } \\
\text { risk? }\end{array}$ & stock price cash risk & $\begin{array}{l}\text { keragaman gender dewan } \\
\text { berpengaruh } 196 \text { negatif } \\
\text { terhadap stock price cash } \\
\text { risk }\end{array}$ \\
\hline $\begin{array}{l}\text { (Shoham et al., } \\
\text { 2020) }\end{array}$ & $\begin{array}{l}\text { Bagaimana } \\
\text { pengaruh } \\
\text { keragaman gender } \\
\text { dewan terhadap } \\
\text { cross listing? }\end{array}$ & cross listing & $\begin{array}{l}\text { keragaman gender dewan } \\
\text { berpengaruh } 196 \text { negatif } \\
\text { terhadap cross listing }\end{array}$ \\
\hline
\end{tabular}




\begin{tabular}{|c|c|c|c|}
\hline $\begin{array}{l}\text { (van den Oever \& } \\
\text { Beerens, 2020) }\end{array}$ & $\begin{array}{l}\text { Bagaimana } \\
\text { pengaruh } \\
\text { keragaman gender } \\
\text { dewan terhadap } \\
\text { organizational } \\
\text { performance? }\end{array}$ & $\begin{array}{l}\text { organizational } \\
\text { performance }\end{array}$ & $\begin{array}{l}\text { keragaman gender dewan } \\
\text { berpengaruh positif terhadap } \\
\text { organizational performance }\end{array}$ \\
\hline $\begin{array}{l}\text { Wang, Wilson, } \\
\text { dan Li (2020) }\end{array}$ & $\begin{array}{l}\text { Bagaimana } \\
\text { pengaruh } \\
\text { keragaman gender } \\
\text { dewan terhadap } \\
\text { corporate } \\
\text { environmental } \\
\text { responsibility? }\end{array}$ & $\begin{array}{l}\text { corporate } \\
\text { environmental } \\
\text { responsibility }\end{array}$ & $\begin{array}{l}\text { keragaman gender dewan } \\
\text { berpengaruh positif terhadap } \\
\text { corporate environmental } \\
\text { responsibility }\end{array}$ \\
\hline Dobija dkk (2021) & $\begin{array}{l}\text { Bagaimana } \\
\text { pengaruh } \\
\text { keragaman gender } \\
\text { dewan terhadap } \\
\text { financial reporting } \\
\text { quality? }\end{array}$ & $\begin{array}{l}\text { financial reporting } \\
\text { quality }\end{array}$ & $\begin{array}{l}\text { keragaman gender dewan } \\
\text { berpengaruh positif terhadap } \\
\text { financial reporting quality }\end{array}$ \\
\hline $\begin{array}{l}\text { Nguyen, Nguyen, } \\
\text { Nguyen, dan } \\
\text { Truong }(2021)\end{array}$ & $\begin{array}{l}\text { Bagaimana } \\
\text { pengaruh } \\
\text { keragaman gender } \\
\text { dewan terhadap } \\
\text { firm performance? }\end{array}$ & firm performance & $\begin{array}{l}\text { keragaman gender dewan } \\
\text { berpengaruh positif terhadap } \\
\text { firm performance pada } \\
\text { negara dengan high national } \\
\text { governance quality dan } \\
\text { sebaliknya negative }\end{array}$ \\
\hline
\end{tabular}

\section{PEMBAHASAN}

Penelitian-penelitian diatas, beberapa diantaranya, menunjukkan hasil yang tidak sama atau bertentangan, yaitu board gender diversity berpengaruh positif terhadap corporate risk (Poletti-Hughes dan Briano-Turrent, 2019), sedangkan board gender diversity tidak berpengaruh terhadap firm risk (Sila, Gonzalez, dan Hagendorff, 2015). Hal ini disebabkan adanya perbedaan sampel dan tempat penelitian, serta adanya beberapa variabel yang dikontrol pada penelitian Poletti-Hughes dan BrianoTurrent (2019) sehingga memberikan hasil yang berbeda dibandingkan penelitian Sila, Gonzalez, dan Hagendorff (2015).

Penelitian yang menunjukkan hasil berlawanan juga ditunjukkan oleh Saeed dan Sameer (2017) dimana board gender diversity berpengaruh negatif terhadap dividend payments, sedangkan pada penelitian Ye dkk (2019) board gender diversity berpengaruh positif terhadap dividend payouts. Hal ini disebabkan adanya perbedaan tempat penelitian beserta sampelnya, dan terdapat beberapa variabel yang dikontrol pada penelitian Ye dkk (2019) sehingga memberikan hasil yang berbeda dibandingkan penelitian Saeed dan Sameer (2017).

Penelitian selanjutnya yang menunjukkan hasil yang tidak sama yaitu pada penelitian van den Oever dan Beerens (2020), dapat diketahui hasilnya bahwa board gender diversity memiliki pengaruh positif terhadap organizational performance. Hasil berbeda disampaikan oleh Nguyen, Nguyen, Nguyen, dan Truong (2021) pada penelitian mereka yaitu board gender diversity berpengaruh negatif pada firm performance pada negara dengan low national governance quality. Perbedaan ini disebabkan karena Nguyen dkk (2021) membedakan negara dengan high dan low national governance quality, yang memberikan hasil penelitian yang berbeda.

\section{KESIMPULAN}

Hasil penelitian-penelitian terdahulu memperlihatkan pengaruh positif board gender diversity terhadap stock price informativeness, firm performance, sustainability reporting quality, internal control weaknesses, corporate social responsibility (CSR), CEO's base pay dan compensation inequality, corporate risk, dividend payouts, renewable energy consumption, corporate innovation, firm 
profitability, biodiversity disclosures, cross listing, organizational performance, corporate environmental responsibility, financial reporting quality, firm performance pada negara dengan high national governance quality. Hasil penelitian-penelitian sebelumnya seperti tersebut diatas juga menunjukkan bahwa board gender diversity berpengaruh negatif terhadap dividend payments, capital structure, technical efficiency, $R \& D$ investments, cost of bank loans, stock price cash risk, firm performance pada negara dengan low national governance quality. Hasil selanjutnya adalah firm risk tidak dipengaruhi oleh board gender diversity. Penelitian-penelitian diatas, beberapa diantaranya, menunjukkan hasil yang tidak sama atau bertentangan, yaitu pengaruh positif board gender diversity terhadap corporate risk (Poletti-Hughes dan Briano-Turrent, 2019), sedangkan firm risk tidak dipengaruhi board gender diversity (Sila, Gonzalez, dan Hagendorff, 2015), selanjutnya Saeed dan Sameer (2017) dimana board gender diversity berpengaruh negatif terhadap dividend payments, sedangkan pada penelitian Ye dkk (2019) pengaruh positif board gender diversity terhadap dividend payouts, serta penelitian van den Oever dan Beerens (2020), hasilnya menunjukkan bahwa pengaruh positif board gender diversity terhadap organizational performance, yang berbeda dengan Nguyen dkk (2021) pada penelitian mereka yaitu board gender diversity berpengaruh negatif pada firm performance pada negara dengan low national governance quality. Hal ini disebabkan adanya perbedaan sampel dan tempat penelitian, serta adanya beberapa variabel yang dikontrol pada penelitian yang lebih baru sehingga memberikan hasil yang berbeda dibandingkan penelitian sebelumnya.

\section{SARAN:}

1. Saran Teoritis: Saran untuk peneliti selanjutnya adalah dapat membandingkan sistem tata kelola perusahaan berbasis pemegang saham seperti Amerika Serikat, Inggris dan Australia, meneliti mekanisme dimana keragaman dewan mempengaruhi kinerja organisasi, memperdalam wawancara dengan anggota dewan, pemegang saham, eksekutif, dan pemangku kepentingan yang lain tentang inisiatif corporate biodiversity dan menambah rentang waktu studi literatur, misalnya 30 tahun terakhir. Melakukan penggalian secara mendalam tentang faktor-faktor apa yang membedakan board gender diversity di Negara-negara maju dengan Negara-negara berkembang.

2. Saran Praktis: memberikan gambaran praktis bagi Pemerintah bahwa variable national governance quality menjadi faktor eksternal yang mampu mempengaruhi kondisi kinerja Perusahaan. Banyak kebijakan Perusahaan yang mempertimbangkan tentang national governance quality, jika penerapannya tinggi maka akan mendukung terhadap kinerja keuangan Perusahaan namun sebaliknya jika rendah maka akan memiliki efek negative bagi perkembangan kinerja keuangan Perusahaan.

\section{REFERENSI}

Adusei, M. (2019). Board gender diversity and the technical efficiency of microfinance institutions: Does size matter? International Review of Economics and Finance, 64(August), 393-411. https://doi.org/10.1016/j.iref.2019.07.008

Adusei, M., \& Obeng, E. Y. T. (2019). Board gender diversity and the capital structure of microfinance institutions: A global analysis. Quarterly Review of Economics and Finance, 71, 258-269. https://doi.org/10.1016/j.qref.2018.09.006

Al-Shaer, H., \& Zaman, M. (2016). Board gender diversity and sustainability reporting quality. Journal of Contemporary Accounting and Economics, 12(3), 210-222. https://doi.org/10.1016/j.jcae.2016.09.001

Almor, T., Bazel-Shoham, O., \& Lee, S. M. (2020). The dual effect of board gender diversity on R\&D investments. Long Range Planning, March, 101884. https://doi.org/10.1016/j.1rp.2019.05.004

Atif, M., Hossain, M., Alam, M. S., \& Goergen, M. (2020). Does board gender diversity affect renewable energy consumption? Journal of Corporate Finance, August 2018. https://doi.org/10.1016/j.jcorpfin.2020.101665 
Attah-Boakye, R., Adams, K., Kimani, D., \& Ullah, S. (2020). The impact of board gender diversity and national culture on corporate innovation: A multi-country analysis of multinational corporations operating in emerging economies. Technological Forecasting and Social Change, 161(August), 120247. https://doi.org/10.1016/j.techfore.2020.120247

Chen, Y., Eshleman, J. D., \& Soileau, J. S. (2016). Board Gender Diversity and Internal Control Weaknesses. Advances in Accounting, 33, 11-19. https://doi.org/10.1016/j.adiac.2016.04.005

Geletkanycz, M. A. (2020). Social movement spillover: Barriers to board gender diversity posed by contemporary governance reform. Leadership Quarterly, 31(6). https://doi.org/10.1016/j.leaqua.2020.101438

Gul, F. A., Srinidhi, B., \& Ng, A. C. (2011). Does board gender diversity improve the informativeness of stock prices? Journal of Accounting and Economics, 51(3), 314-338. https://doi.org/10.1016/j.jacceco.2011.01.005

Haque, F., \& Jones, M. J. (2020). European firms' corporate biodiversity disclosures and board gender diversity from 2002 to 2016. British Accounting Review, 52(2), 100893. https://doi.org/10.1016/j.bar.2020.100893

Low, D. C. M., Roberts, H., \& Whiting, R. H. (2015). Board gender diversity and firm performance: Empirical evidence from Hong Kong, South Korea, Malaysia and Singapore. Pacific Basin Finance Journal, 35, 381-401. https://doi.org/10.1016/j.pacfin.2015.02.008

Maria Giuseppina Brunaa, \& Rey Đặng, Aymen Ammari, L. H. (n.d.). The effect of board gender diversity on corporate social performance, An instrumental variable quantile regression approach. https://doi.org/10.1016/j.frl.2020.101734

Nekhili, M., Nagati, H., Chtioui, T., \& Nekhili, A. (2017). Gender-diverse board and the relevance of voluntary CSR reporting. International Review of Financial Analysis, 50(2016), 81-100. https://doi.org/10.1016/j.irfa.2017.02.003

Owen, A. L., \& Temesvary, J. (2019). CEO compensation, pay inequality, and the gender diversity of bank board of directors. Finance Research Letters, 30, 276-279. https://doi.org/10.1016/j.frl.2018.10.010

Poletti-Hughes, J., \& Briano-Turrent, G. C. (2019). Gender diversity on the board of directors and corporate risk: A behavioural agency theory perspective. International Review of Financial Analysis, 62(August 2018), 80-90. https://doi.org/10.1016/j.irfa.2019.02.004

Qayyum, A., Rehman, I. U., Shahzad, F., Khan, N., Nawaz, F., Kokkalis, P., \& Sergi, B. S. (2020). Board gender diversity and stock price crash risk: Going beyond tokenism. Borsa Istanbul Review. https://doi.org/10.1016/j.bir.2020.10.010

Rastad, M., \& Dobson, J. (2020). Gender diversity on corporate boards: Evaluating the effectiveness of shareholder activism. Quarterly Review of Economics and Finance. https://doi.org/10.1016/j.qref.2020.09.007

Rey Đặng, L’Hocine Houanti, Krishna Reddy, M. S. (n.d.). Does board gender diversity influence firm profitability - A control function approach. https://doi.org/10.1016/j.econmod.2020.05.009

Saeed, A., \& Sameer, M. (2017). Impact of board gender diversity on dividend payments: Evidence from some emerging economies. International Business Review, 26(6), 1100-1113. https://doi.org/10.1016/j.ibusrev.2017.04.005

Şener, İ., \& Karaye, A. B. (2014). Board Composition and Gender Diversity: Comparison of Turkish and Nigerian Listed Companies. Procedia - Social and Behavioral Sciences, 150, 1002-1011. https://doi.org/10.1016/j.sbspro.2014.09.112 
Shoham, A., Lee, S. M., Khan, Z., Tarba, S. Y., \& Ahammad, M. F. (2020). The effect of board gender diversity on cross-listing. Journal of Corporate Finance, 65, 101767. https://doi.org/10.1016/j.jcorpfin.2020.101767

Sila, V., Gonzalez, A., \& Hagendorff, J. (2016). Women on board: Does boardroom gender diversity affect firm risk? Journal of Corporate Finance, 36, 26-53. https://doi.org/10.1016/j.jcorpfin.2015.10.003

Snyder, H. (2019). Literature review as a research methodology: An overview and guidelines. Journal of Business Research, 104(August), 333-339. https://doi.org/10.1016/j.jbusres.2019.07.039

Tyrowicz, J., Terjesen, S., \& Mazurek, J. (2020). All on board? New evidence on board gender diversity from a large panel of European firms. European Management Journal, 38(4), 634-645. https://doi.org/10.1016/j.emj.2020.01.001

van den Oever, K., \& Beerens, B. (2020). Does task-related conflict mediate the board gender diversityorganizational performance relationship? European Management Journal, xxxx. https://doi.org/10.1016/j.emj.2020.09.008

Ye, D., Deng, J., Liu, Y., Szewczyk, S. H., \& Chen, X. (2019). Does board gender diversity increase dividend payouts? Analysis of global evidence. Journal of Corporate Finance, 58(April), 1-26. https://doi.org/10.1016/j.jcorpfin.2019.04.002 